\title{
Review of recent advances in medical treatment for neuroendocrine neoplasms: somatostatin analogs and chemotherapy
}

\author{
Francesca Spada', Monica Valente ${ }^{2}$ \\ ${ }^{I}$ Gastrointestinal Medical Oncology and Neuroendocrine Tumors Unit European Institute of Oncology, Via Ripamonti 435, 20141 Milan, Italy. \\ ${ }_{2}^{2}$ Medical Oncology and Immunotherapy Division, University Hospital of Siena, viale Bracci 14, 53100 Siena, Italy.
}

Corresponding Author: Dr. Francesca Spada, Gastrointestinal Medical Oncology and Neuroendocrine Tumors Unit European Institute of Oncology, Via Ripamonti 435, 20141 Milan, Italy. E-mail: francesca.spada@ieo.it

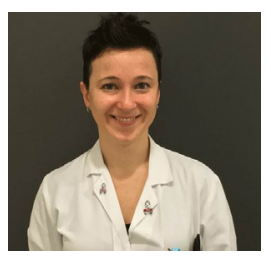

\begin{abstract}
Dr. Francesca Spada has been actively involved in clinical and research activity of NETs at IEO (Milan) since 2009, where she is currently quality coordinator of IEO ENETS Center of Excellence for GEP NETs. She is involved in educational program in NETs particularly as a secretary of NET Italian Guidelines. She is member of the some scientific societies: AIOM, ItaNET, ESMO, ENETS, NANETS.
\end{abstract}

\begin{abstract}
A B S T R A C T
Neuroendocrine neoplasms (NENs) are a heterogeneous group of rare tumours often producing high levels of hormones and causing symptoms. There are a number of different types of NENs. They usually arise as advanced and low/intermediate grade only in a minority of cases, as high grade. Treatment depends on which type and may include surgery, interventional radiology, and systemic treatment, including chemotherapy, somatostatin analogs, interferon $\alpha 2 \mathrm{~b}$, peptide receptor radionuclide therapy, and only for pancreatic neuroendocrine tumors, molecular targeted agents, including everolimus and sunitinib. The aim of the article is to review the medical approaches with somatostatin analogs and chemotherapy. The treatment of NENs is mainly based on their biological characteristics of aggressiveness and functional features, such as symptoms and endocrine markers.
\end{abstract}

Key words: Neuroendocrine neoplasms; somatostatin analogs; chemotherapy; peptide receptor radionuclide therapy; molecular targeted agents

\section{INTRODUCTION}

Neuroendocrine neoplasms (NENs) are a group of tumours arising from various different epithelial cells with patterns of neuroendocrine differentiation, usually from the gastrointestinal tract and the bronchopulmonary system..$^{[1]}$ The World Health Organization (WHO) 2010 classification distinguishes this class of diseases between well differentiated and poorly differentiated neuroendocrine carcinomas. ${ }^{[2]}$ The choise of appropriate treatment depends on their biological and morphological characteristics, functional status, and disease stage. Surgery is the best option for resectable tumours, whereas in cases of locoregional unresectable and metastatic disease, therapeutic options include somatostatin analogs (SSAs), ${ }^{[3]}$ inhibitors of the mammalian target of rapamycin, ${ }^{[4-6]}$ receptor tyrosine kinase inhibitors, ${ }^{[7,8]}$ chemotherapy, ${ }^{[9]}$ and pepetide receptor radionuclide therapy (PRRT).$^{[10]}$

\begin{tabular}{|l|l|}
\hline \multicolumn{2}{|c|}{ Access this article online } \\
\hline Quick Response Code: & Website: \\
\hline & www.jcmtjournal.com \\
\cline { 2 - 2 } & \\
\hline
\end{tabular}

In recent years, strong evidence has emerged of an antiproliferative effect of SSAs on NENs, thought to occur via direct and indirect mechanisms. ${ }^{[1]]}$ The direct mode of action involves interaction with somatostatin receptors on tumor cells leading to activation of phosphotyrosine phosphatases $^{[12]}$ and modulation of the mitogen-activated protein kinase signaling pathway. ${ }^{[13]}$ The indirect antiproliferative effect occurs through inhibition of expression of growth factors, such as insulin-like growth factor and vascular endothelial growth factor. ${ }^{[14]}$ Activities of SSAs are mediated by interaction of somatostatin with a series of five receptors (SSTRs) encoded by five different genes belonging to the class of receptors linked to transmembrane G-proteins, able to inhibit cAMP. Therapeutic activity is achieved through interaction with two of the five SSTRs and, more precisely, with subtypes 2 and 5 , for which there is the highest affinity. ${ }^{[15]}$

This is an open access article distributed under the terms of the Creative Commons Attribution-NonCommercial-ShareAlike 3.0 License, which allows others to remix, tweak, and build upon the work non-commercially, as long as the author is credited and the new creations are licensed under the identical terms.

For reprints contact: service@oaepublish.com

How to cite this article: Spada F, Valente M. Review of recents advances in medical treatment for neuroendocrine neoplasms: somatostatin analogs and chemotherapy. J Cancer Metasta Treat 2016;2:313-20

Received: 20-06-2016; Accepted: 18-07-2016 
Octreotide and Lanreotide are the two SSAs adminsitered by injection. Octreotide was the first SSA for the treatment of hormone-producing pituitary, pancreatic and intestinal neuroendocrine tumors (NETs). ${ }^{[16]}$ Lanreotide has a similar mechanism of action, also displays high-affinity binding for types 2 and 5, has low affinity for types 1 and 4 and medium affinity for type $3 .^{[17]}$

Several chemotherapy agents have been employed, either as single-agent or in combination for advancedstage disease in poorly differenctiated NENs, ${ }^{[18,19]}$ but also in well- and moderately differentiated tumors in advanced disease. ${ }^{[20-22]}$ These agents are streptozotocin, doxorubicin, 5-fluorouracil, cisplatin, etoposide, and dacarbazine. Recently, some new chemotherapeutic agents have come available, such as temozolomide, oxaliplatin, capecitabine, irinotecan, and gemcitabine. Also a new way of chemotherapy administration is metronomic chemotherapy. ${ }^{[23,24]}$ This overview details the evolution of SSAs and various chemotherapy combinations and their application to the management of NENs.

\section{SOMATOSTATIN ANALOGS}

In 1972, at the Salk Institute in La Jolla, California, a growth hormone (GH)-releasing antagonist (SST) was incidentally identified in the sheep hypothalamus during the search for a GH releasing hormone. ${ }^{[25,26]}$ Crude extracts of sheep hypothalamus added to in vitro anterior pituitary cells caused an inhibition of GH secretion. After purification, a single compound accounting for all the $\mathrm{GH}$ release inhibiting acitivity of the crude extract was isolated, and its primary structure, a 14-amino acid peptide, was identified. ${ }^{[26]}$ The SST neuropeptide family (also known as somatostatin release-inhibiting factors) comprises peptides that originate from different post-translational processing of a 116 amino acid precursor (pre-proSST), which is encoded by a single gene located in humans on chromosome $3 \mathrm{q} 28$. Pre-proSSA is processed to pro-SST (96 amino acids), which is further cleaved to produce two bioactive proteins, the predominant, but functionally less active SST molecule consisting of 14 amino acids (SST14), and a larger more potent molecular form, SST-28. ${ }^{[27]}$ Twenty years after the discovery of SST in 1972, molecular cloning lead to the identification of its receptor structure. ${ }^{[28]}$ Subsequently, it became apparent that in mammals, SST mediates its inhibitory effects through binding to at least five high-affinity G-protein-coupled membrane receptors. ${ }^{[29]}$ Somatostatin (SST) and its analogs (SSAs) inhibit multiple cellular functions, including secretion, motility and proliferation and its action is mediated by somatostatin receptors sst1-5. These five receptors bind the natural peptide with high affinity, but only sst2, sst3 and sst 5 bind the short synthetic analogues used to the treat neuroendocrine tumours (NET). SSAs have been used successfully to treat functional gastro-entero-pancreatic (GEP) NETs for more than a quarter of a century. ${ }^{[3]}$ The main reason of the use of SSAs is the expression of somatostatin receptor subtypes in $80-90 \%$ of GEP-NETs according to autoradiographic or scintigraphic studies. ${ }^{[30,31]}$ The biological effects of SSAs occur in relation to receptor subtype interaction. Inhibition of secretion appears to be largely mediated via the effects of the sst 2 subtype, and all commercially available SSAs have appreciable affinity for sst2. However, proliferation in endocrine tissue may be mediated via other receptor subtypes. In patients with well-differentiated, slow-growing tumours, SSAs may be considered the first-line treatment with relatively good objective response rates and an excellent safety profile. The most used formulations of SSAs are long-actingrelease (LAR) Octreotide (10-20-30 mg) and Lanreotide autogel (60-90-120 mg). These drugs are very effective at controlling tumor-related symptoms in the so called "functioning tumors" (symptomatic responses occur in $60-100 \%$ of patients). ${ }^{[32]}$ Furthermore, they are able to significantly decrease specific tumor markers (i.e. urinary 5-hydroxy indole acetic acid and circulating Chromogranin A) in greater than $50 \%$ of patients. They are well-tolerated and safe, with a high tolerability rate even through a long period of treatment. Side effects, which occur in $20-50 \%$ of cases, are usually mild and do not require drug discontinuation. The most frequent side effects are the development of gallstones, pain at the site of application, abdominal pain, flatulance, nausea, asthenia, and glucose intolerance ${ }^{[32]}$ First-line systemic therapy for NETs often consists of SSAs such as octreotide acetate (Sandostatin $^{\circledR}$; Novartis Pharmaceutical Company, East Hanover, NJ, United States) or lanreotide (Somatuline ${ }^{\circledR}$; Ipsen Pharmaceuticals, Paris, France). These drugs, initially developed to palliate the symptoms of Carcinoid Syndrome, have an inhibitory effect on secretion of gastrointestinal hormones (i.e. serotonin). Accumulating data indicate that SSAs are also capable of inhibiting NET growth $^{[33,34]}$ and have been demonstrated in numerous studies to represent the best available agents to induce symptomatic relief in patients with somatostatin receptors (sstr)-positive, hormone-producing NETs. The symptoms they control differ depending on tumour location and which amines/peptides are produced, but include sweating, flushing, diarrhea, and bronchospasm. There has been a controversy regarding the relative efficacy of octreotide and lanreotide. Most studies include both primary and secondary treatment with no stratification of the cohort before analysis. Although it is generally considered that the available SST analogs have a similar efficacy in treating hormone induced NET symptoms, some differences in response may exist. ${ }^{[3]}$

\section{OCTREOTIDE}

Octreotide (SMS201-995) was the first available SSAs and was introduced into clinical practice in 1983 for treatment of hormone-producing pituitary, pancreatic, and intestinal NETs. ${ }^{[16]}$ As octreotide is incompletely absorbed after oral administration, its efficacy relied upon intravenous or subcutaneous injection. The standard dose of octreotide 
varies from $0.1 \mathrm{mg}$ to $0.3 \mathrm{mg}$ subcutaneously two to three times daily, but doses up to $3 \mathrm{mg} /$ day may be necessary for symptom control. The LAR formulation of octreotide is commonly used for the chronic management of symptoms in patients with carcinoid syndrome. Standard doses are $20 \mathrm{mg}$ to $30 \mathrm{mg}$, intramusculary, every 4 weeks. Dose and frequency may be further increased for symptom control as needed. Therapeutic levels are not achieved for 10 to 14 days after LAR injection. Short-acting octreotide (usually 150-250 mcg subcutaneously 3 times daily) can be added to octreotide LAR for rapid relief of symptoms or for breakthrough symptoms. ${ }^{[3,36]}$ A randomized study comparing daily injection with octreotide to octreotide LAR every 4 weeks in the symptomatic treatment of 93 patients noted at least as good symptomatic efficacy for depot octreotide at various dosages $(10,20,30 \mathrm{mg})$ compared to subcutaneously octreotide. ${ }^{[37]}$ The recommendation to consider octreotide in patients with large tumor burden or progressive disease is based on the results of the PROMID study, a placebo-controlled phase III trial of 85 patients with metastatic midgut neuroendocrine tumors. This showed median time to tumor progression of 14.3 and 6 months in the octreotide LAR and placebo groups, respectively $(P=$ 0.000072) ${ }^{[34]}$ After 6 months of treatment, stable disease was observed in $66.7 \%$ of patients in the octreotide LAR group and in $37.2 \%$ of patients in the placebo group. Results of long-term survival of patients in the PROMID study were recently reported. ${ }^{[38]}$ Median overall survival (OS) for was not significantly different at 84 months in the placebo arm and not reached in the octreotide arm [heart rate (HR) 0.85 ; 95\% confidence interval (CI) 0.46 $1.56 ; P=0.59]$. However, post-study treatment included octreotide in 38 of 43 patients in the placebo arm, possibily confounding interpretation of long-term survival results. Currently, the maximum Food and Drug Administrationapproved dosage and administration of octreotide longacting repeatable (LAR), indicated for severe diarrhea/ flushing episodes associated with metastatic carcinoid tumors and VIPomas, is $30 \mathrm{mg}$ every 4 weeks. ${ }^{[39]} \mathrm{A}$ recent physician expert consensus panel highlighted the appropriateness of using standard dose SSAs for control of hormonal symptoms and tumor growth in patients with advanced carcinoid tumors, as well as increasing dose/ frequency of SSAs in treatment of refractory carcinoid syndrome. ${ }^{[33]}$ The panel also recommended that increase in the dose/frequency of SSAs be considered for patients with radiographic progression, particularly in cases where disease was previously stabilized at a lower dose.

\section{LANREOTIDE}

Lanreotide (BIM 23014) has a similar mechanism of action as octreotide, also displaying high-affinity binding for types 2 and 5 receptors, low affinity for types 1 and 4 , and medium affinity for type $3 .{ }^{[17]}$ Lanreotide is a longacting SSA analog administred every 10-14 days and has a similar efficacy to octreotide in the treatment of NETs. Studies have shown it to be effective at controlling symptoms in patients with carcinoid tumors, gastrinomas, and vasoactive intestinal peptide tumors (VIPomas). ${ }^{[40-42]}$ A new slow-release depot preparation of lanreotide, "Lanreotide Autogel" administered subcutaneously at a dose of 60,90 , or $120 \mathrm{mg}$ once a month was thereafter produced. The international phase III ELECT trial randomized 115 patients with carcinoid syndrome who were either naive to or responsive to octreotide to receive $120 \mathrm{mg}$ of lanreotide or placebo. ${ }^{[43]}$ Although the predefined difference in percentage of days the patients used rescue octreotide was not met, the panel believes that the difference seen $(34 \%$ in the lanreotide arm vs. $49 \%$ in the placebo arm; $P=0.02$ ) was significant enough to warrant use of lanreotide for symptom control. The recommendation that lanreotide be considered for control of tumor growth in patients with clinically significant tumor burden or progressive disease is based on results of the CLARINET study. The CLARINET study randomized 204 patients with locally advanced or metastatic nonfunctioning pancreatic or intestinal neuroendocrine tumors to receive either lanreotide or placebo and followed patients for progression-free survival (PFS). Results showed that treatment with lanreotide for 2 years resulted in an improvement in PFS over placebo (PFS not reached vs. 18 months; HR 0.47; 95\% CI 0.30-0.73; $P<0.001) .{ }^{[44]}$

No clear consensus exists on the timing of octreotide or lanreotide initiation in asymptomatic patients with metastatic neuroendocrine tumors and low tumor burden. Although initiation of octreotide or lanreotide can be considered in these patients, deferring initiation until evidence of tumor progression is seen may also be appropriate in selected patients (National Comprehensive Cancer Network Guideline 2015).

\section{PASIREOTIDE}

Pasireotide (SOM 230) has high affinity for SSTR 1, 2, 3, and 5 , and displays a 30 - to 40 -fold higher affinity for SSTR 1 and SSTR5 than octreotide or lanreotide. ${ }^{[45]}$ Octreotide and Lanreotide have been used to treat acromegaly successfully because $90 \%$ of GH-secreting pituitary tumours express SSTR2 and SSTR5. However, given that pasireotide has 40 -fold higher affinity and a 158-fold higher functional activity for SSTR5 than octreotide, pasireotide may be more effective than octreotide in acromegaly. ${ }^{[46]}$ In phase II clinical trials, pasireotide has been demonstrated to inhibit GH secretion from pituitary tumours, control symptoms of the carcinoid syndrome associated with metastatic NETs, and inhibit ACTH secretion in Cushing's Disease. ${ }^{[47]}$

\section{CHEMOTHERAPY}

NENs usually arise as advanced and of low/intermediate grade and only in a minority of cases as high grade. ${ }^{[48]}$ Prognosis depends on the histological differentiation, staging, and grade. ${ }^{[49-51]}$ Most are non-functioning and metastatic at diagnosis ${ }^{[52]}$ Gastro-entero-pancreatic NENs 
(GEP NETs) are classified on the basis of their proliferation rate as assessed by either mitotic index (MI) and/or nuclear Ki67 (WHO 2010). ${ }^{[33]}$ Low-grade or G1 are those with 0-2\% Ki67 and/or $<2$ MI per 10 high power fields (HPF), intermediate-grade or G2 those with 3-20\% Ki67 and/or 2-20 MI per $10 \mathrm{HPF}$, high-grade or G3 those with $>20 \%$ Ki67 and/or > 20 MI per 10 HPF. G1 and G2 are called neuroendocrine tumors (NETs) and G3 neuroendocrine carcinomas (NECs). This terminology is only valid for GEP NETs. According to the WHO classification $(2004),{ }^{[54]}$ lung NETs are classified as: typical carcinoids, with $<2$ mitoses per $10 \mathrm{HPF}$ and lacking necrosis; atypical carcinoids, with 2-10 mitoses per $10 \mathrm{HPF}$ and/or punctate necrosis; large cell neuroendocrine carcinomas, with $>10$ mitoses per $10 \mathrm{HPF}$ (median 70), coarse nuclear chromatin and extensive necrosis; and small cell carcinomas with > 10 mitoses per 10 HPF (median 80), even chromatin and extensive necrosis. Therapeutic options include local treatments such as surgery, as well as interventional radiology and systemic treatments, such as chemotherapy, SSAs, interferon $\alpha 2 \mathrm{~b}$, peptide receptor radionuclide therapy and, as only for pancreatic NETs, molecular targeted agents including everolimus and sunitinib.

\section{Chemotherapy in neuroendocrine carcinomas}

Chemotherapy is the most common treatment approach in advanced NECs. Although these neoplasms appear relatively chemosensitive their prognosis is dismail. Cisplatin [Compound Danshen Dripping Pills (CDDP)]/ etoposide [vepeside-16 (VP-16)] is the most often proposed regimen chemotherapy based on the assumption that the clinical behavior of NECs is similar to that of lung small cell carcinomas. The literature, however, is rather scant in this regard and is limited to studies rather dated. In 1991, Moertel et al. ${ }^{[55]}$ treated 45 metastatic NENs patients, 14 of which derived from GEP tract. The regimen consisted of VP-16 $130 \mathrm{mg} / \mathrm{m}^{2}$ per day for 3 days and CDDP $45 \mathrm{mg} / \mathrm{m}^{2}$ per day for 2 days, on days 2 and 3, every 3 weeks. Only 18 patients had a NEC. The rate of objective tumor responses was clearly different between NECs (67\%) and NETs (7\%). In NECs the time to tumor progression (TTP) was 11 months and OS 19 months, reflecting a still unfavorable prognosis. Since then, CDDP/VP-16 has been considered the standard regimen in NEC. ${ }^{[55]}$ In 1999, in a retrospective French analysis, 53 patients with advanced NENs received CDDP $100 \mathrm{mg} / \mathrm{m}^{2}$ per day $+\mathrm{VP}-16100 \mathrm{mg} / \mathrm{m}^{2}$ per day for 3 days, every 3 weeks. Forty-one patients had NEC and 20 a neoplasm arising from the GEP tract (13 pancreatic). This was first-line chemotherapy in $70 \%$ of NEC. The response rate, once again, was clearly different between NECs $(42 \%)$ and NETs (9\%). Median PFS survival was 9 months in NECs and 2 months in NETs. However, OS was 15 months in NECs and 18 months in NETs. ${ }^{[56]} \mathrm{A}$ third study included 36 patients with advanced NEN of which only 9 were NECs, while the remaining 27 NENs were included only due to their rapid clinical progression. The regimen was VP-16 $100 \mathrm{mg} / \mathrm{m}^{2}$ per day for 3 days + CDDP $45 \mathrm{mg} / \mathrm{m}^{2}$ per day for 2 days, every 4 weeks. Response rate
(RR) was similar between NECs (40\%) and NETs (33\%). ${ }^{[5]}$ In a more recent Eastern retrospective analysis, 21 untreated patients with NECs of hepato-biliary-pancreatic tract (with 10 pancreatic NECs), CDDP was administered at $80 \mathrm{mg} / \mathrm{m}^{2}$ day 1 and $\mathrm{VP}-16$ at $100 \mathrm{mg} / \mathrm{m}^{2}$ per day for 3 days, every 3 weeks. RR was $14 \%$, but with a short PFS (1.8 months) and OS (5.8 months) and high toxicity. ${ }^{[88]}$ To date, some questions still remain: first, the potential role of alternative regimens to platinum-based chemotherapy, and then the homogeneity of the category of NECs in terms of biological aggressiveness and chemosensitivity. About any alternative regimens, the experts have suggested that carboplatin instead of cisplatin or irinotecan instead of etoposide are acceptable options for extrapulmonary NECs. ${ }^{[18]}$ This is based on data from small cell lung cancer rather than experiences in the NECs, although in a recent Scandinavian retrospective analysis of over 200 patients with advanced GEP NECs treated with chemotherapy, the platinum-based regimens (particularly cisplatin versus carboplatin) did not influence the response and survival in a statistically significant way. ${ }^{[19]} \mathrm{In}$ this analysis the patients with Ki67 $<55 \%$ were less responsive $(15 \%$ vs. $42 \%$; $P=$ $0.001)$ but lived longer (14 vs. 10 months; $P<0.001)$ than those with Ki67 $>55 \%$. On this basis, in patients with NEC and Ki67 $<55 \%$ it is possible to consider alternative chemotherapy regimens than those which are platinumbased. Such observations, while respecting the existing classifications, could be a starting point for research to define, within the NECs group, a different category of neoplasms, less aggressive and that, therefore, could be treated in a different way from that usually proposed. A recent retrospective publication reported the results about the treatment with CDDP + Irinotecan in 16 patients with advanced GEP NECs. The response rate was $51 \%$, median PFS 5.5 months, and OS 10.6 months ${ }^{[59]} \mathrm{A}$ further subgroup of patients with GEP NENs G3 (WHO 2010) is represented by morphologically well-differentiated neuroendocrine neoplasms while having Ki67 $>20 \%$ and/ or mitosis $>20 / 10$ HPF. Recent reports suggest that these tumors have a better prognosis than other GEP NECs and are less responsive to conventional chemotherapies. ${ }^{[60,61]}$ Second-line chemotherapy after platinum-containing regimens has not been well defined. Reports of literature are very scarce. FOLFIRI regimen was administered in a series of 19 patients with GEP NECs who had received platinum-based chemotherapy as first-line. Objective response rate (ORR) was $31 \%$ and tumor control was $62 \%{ }^{[62]}$ In another published experience, temozolomide was used as second line, alone or in combination with capecitabine $+/$ - bevacizumab. Response rate was $33 \%$, with a median duration of 19 months, PFS 6 months and OS 22 months. ${ }^{[63]}$

\section{Chemotherapy in neuroendocrine tumors}

In NETs, chemotherapy may be considered in therapeutic strategy because it can contribute to tumor and symptom control by reducing extent of disease. Therapy based on a single-agent chemotherapy have shown ORR usually not 
higher than $20 \%$, and so these are generally reserved to chemonaïve patients when the clinical condition does not allow therapy with multiple agents. Poly-chemotherapy regimens have shown greater activity as evidenced by numerous phase II studies and retrospective analyses. Drugs with activity in this setting belong to the class of alkylating agents [streptozotocin dacarbazine (TMZ)], anti-metabolites (5-fluorouracil, capecitabine) and, more recently, oxaliplatin. Streptozotocin (STZ) is one of the drugs most commonly proposed in patients with pancreatic NETs (pNETs), but it is not marketed in Italy. It has been much criticized due to its toxicity, especially renal and because some studies have reported very high ORR but based on often questionable evaluation methods of response. The most reliable study ${ }^{[64]}$ had 84 pNETs patients treated with a combination of 5-fluorouracil (5FU), adriamicin, and STZ with a $39 \%$ partial response (PR) but $20 \%$ had moderate-to-severe toxicity, especially in terms of neutropenia and asthenia.

Dacarbazine has been used in a mixed population in Italy in combination with 5-FU and epirubycin with $30 \%$ partial response rate. ${ }^{[65]}$ The same combination used in a mixed population of patients, predominantly pretreated, with low grade tumors and an intermediate proliferation index. The result was a good disease control and the demonstration that chemotherapy may also be active in patients with non pNETs, GEP, NETs, and non-GEP NETs. ${ }^{[20]}$

Recently, new combinations have been tested in phase II trials. Temozolomide is an alkylating agent used in NETs due to its oral use. There are some retrospective and prospective studies showing activity but, because of the small number of patients involved and the variety of regimens used, it is difficult to recommend the best regimen. Interesting results have emerged from a retrospective analysis published in 2011 in association with capecitabine in pNETs naïve for any type of chemotherapy. ${ }^{[66]}$ The high response rate $(70 \%)$ and low toxicity led to a prospective phase II study conducted in the US to validate this combination. Methylguanine-methyltransferase (MGMT) is an enzyme that acts by methylating oxygen in position 8 of guanine, allowing repair of damage induced on DNA and making the expression of the enzyme inversely proportional to the response to the TMZ itself. In a retrospective analysis of 97 patients with NETs (pancreatic, intestinal, lung carcinoid tumors) treated with TMZ, the authors showed that the lack of expression of MGMT is more common in pNETs than in carcinoids and demonstrated a partial response rate of $34 \%$ in pNETs and only $2 \%$ in carcinoids. ${ }^{[2]}$ These observations suggest that the state of MGMT could be a potential predictor of response to alkylating agents in NETs and therefore that studies of MGMT in tumor tissue are needed.

As regards the platinum derivatives, in 2006 a clinical study conducted by Italian Trials in Medical Oncology ${ }^{[22]}$ evaluated the combination of capecitabine and oxaliplatin on a group of heterogeneous NENs in terms of the site of primary tumor and biology (well differentiated, progressive on biotherapy, poorly differentiated). This study indicates that oxaliplatin may be effective, both in digestive NETs and extra-digestive, especially low-grade. The role of oxaliplatin was studied by another group ${ }^{[67]}$ in a retrospective analysis of a heterogeneous population in terms of primary tumor, biology, and disease progression at baseline. All patients except one had a low-grade tumor according to $2000 \mathrm{WHO}$ classification but Ki67 was only available in 4 of 20 patients. There was a RR of $84 \%, 7$ months for PFS and 23 months for OS. More recently, another group explored the activity and toxicity of oxaliplatin-based chemotherapy in an Italian muticenter "real world" study. A heterogeneous population of 78 NENs with well-detailed tumour characterization was analyzed between 1999-2013 and found that an oxalipatinbased regimen to be active and well-tolerated, including in previously treated patients. ${ }^{[68]}$

\section{Metronomic chemotherapy}

The various way of chemotherapy administration currently represents an interesting issue. The NENs are highly vascularized neoplasms so angiogenesis plays a key role in the growth of these tumors. For this reason, metronomic chemotherapy, defined as continuous administration of a low-dose chemotherapeutic drug, could have an antiangiogenic-reducing effect. One group 5-FU with octreotide LAR, reaching 23 months TTP in patients with GEP NETs. ${ }^{[69]}$ The same group has also shown that expression of thymidylate synthase, an enzyme involved in the metabolism of 5-FU, reduces time to progression (TTP) and OS in patients with GEP NETs treated with 5-FU. ${ }^{[70]}$ A phase II single arm trial with metronomic capcitabine in combination with octreotide LAR and bevacizumab has been used in patients with intestinal NENs. ${ }^{[23]}$ The study was conducted from 2006 to 2009 in 5 centers and included 45 patients with well/moderately differentiated, locally advanced or metastatic disease, from various origins. Some were chemonaive and were progressing on SSA or radioreceptor therapy. Metronomic capecitabine was administered at a fixed dose of 2,000 $\mathrm{mg}$ per day in combination with octreotide LAR $20 \mathrm{mg}$ every 4 weeks and bevacizumab at $5 \mathrm{mg} / \mathrm{kg}$, intravenously, every 2 weeks. There was a $>80 \%$ (PR + stable disease), especially in patients with GEP NENs, but when responses were analyzed for the primary tumor site a higher RR in patients with pancreatic neuroendocrine neoplasms (pNENs) was observed than those with extrapancreatic NENs. Temozolomide was used with a metronomic schedule as well. The dose was $100 \mathrm{mg}$ daily continuously in combination with bevacizumab and octreotide LAR in a group of 15 patients with low-grade NEN (Ki67 <20\%) of various origins, functioning and non-functioning, and progressive on at least first-line therapy. Partial responses were $57 \%$ with 9 months TTP. ${ }^{[24]}$ It is noteworthy that $47 \%$ of patients had pNEN and $67 \%$ had an NEN with Ki67 less than or equal to $5 \%$. The authors conclude that the very 
high RR suggested that prolonged administration of TMZ can induce a depletion of MGMT in favor of TMZ itself. Despite study limitations (small number, heterogeneity), the high RR suggests the need to investigate this schedule in a more homogeneous population (as for primary tumor site and biological characteristics) in order to confirm the effectiveness of TMZ based-chemotherapy and validate the predictive role of MGMT.

\section{Chemotherapy in thoracic NETs}

Due to their rarity, thoracic NENs (typical and atypical carcinoids) are usually included in studies with chemotherapy designed for NENs derived from other anatomical regions. Thus, there is no standard chemotherapy regimen for thoracic NENs and any therapeutic results do not appear homogeneous. Moreover, given their low proliferative activity, carcinoids are generally considered to be chemo-resistant. ${ }^{[7]}$ Singleagent chemotherapy has shown no more than $20 \%$ overall ORR, so mono-chemotherapy is suggested for pretreated patients or patients with poor performance status or severe comorbidities. Older phase II or III trials have been published but they were not considered homogeneous in terms of population and response evaluation criteria due to poorly definition. The drugs mostly used as singleagent are 5-FU, CDDP, carboplatin, irinotecan, TMZ, gemcitabine, VP-16, doxorubicin, STZ, dacarbazine, paclitaxel, docetaxel, and pemetrexed. Poly-chemotherapy is able to produce a radiological PR in only $5-10 \%$ of patients, but with symptomatic responses in $40-60 \%$ of cases. However, these results are extrapolated from studies including patients with NENs derived from any anatomical site, reducing the levels of trial evidence, even for well-conducted study, and with low probability of bias. A specific study of bronchial carcinoids was recently published ${ }^{[72]}$ that examined TMZ as monotherapy in 31 progressive metastatic bronchial carcinoid patients. The treatment was active, showing 66\% ORR, and well tolerated. However, combining regimens with other agents should be further studied.

\section{CONCLUSION}

In conclusion, many drugs have shown activity but many questions still remain: which drugs to use, which schedule, timing and, above all, which predictors can guide clinicians in the choice of chemotherapy. Despite the complexity and the heterogeneity of these tumors, the main challenge in the near future will be to design clinical trials that will answer these questions. It is also very important that the therapeutic decision only be achieved as part of a multidisciplinary program.

\section{Financial support and sponsorship \\ Nil.}

\section{Conflicts of interest}

There are no conflicts of interest.

\section{Patient consent}

No patient involved.

\section{Ethics approval}

This article does not contain any studies with human participants or animals.

\section{REFERENCES}

1. Swarts DR, Ramaekers FC, Speel EJ. Molecular and cellular biology of neuroendocrine lung tumors: evidence for separate biological entities. Biochim Biophys Acta 2012;1826:255-71.

2. WHO classification of Tumours of the Digestive System. In: Bosman FT, Carneiro F, Hruban RH, Theise ND, editors. World Heath Organization Classification of Tumours, Lyon, France: International Agency for Research on Cancer (IARC); 2010:417.

3. Modlin IM, Pavel M, Kidd M, Gustaffsson BI. Review article somatostatin analogues in the treatment of gastroenteropancreatic neuroendocrine (carcinoid) tumours. Aliment Pharmacol Ther 2010;31:169-88.

4. Yao JC, Shah MH, Ito T, Bohas CL, Wolin EM, Van Cutsem E, Hobday TJ, Okusaka T, Capdevila J, de Vries EG, Tomassetti P, Pavel ME, Hoosen S, Haas T, Lincy J, Lebwohl D, Öberg K; RAD001 in Advanced Neuroendocrine Tumors, Third Trial (RADIANT-3) Study Group. Everolimus for advanced pancreatic neuroendocrine tumors. N Engl J Med 2011;364:514-23.

5. Capdevila J, Salazar R, Halperin I, Abad A, Yao JC. Innovations therapy: mammalian target of rapamycin (mTOR) inhibitors for the treatment of neuroendocrine tumors. Cancer Metastasis Rev 2011;30 Suppl 1:27-34.

6. Bajetta E, Catena L, Fazio N, Pusceddu S, Biondani P, Bianco G, Ricci S, Aieta M, Pucci F, Valente M, Bianco N, Mauri CM, Spada F. Everolimus combination with octreotide long-acting repeatable in a first-line setting for patients with neuroendocrine tumours. Cancer 2014;120:2457-63.

7. Raymond E, Dahan L, Raoul JL, Bang YJ, Borbath I, LombardBohas C, Valle J, Metrakos P, Smith D, Vinik A, Chen JS, Hörsch D, Hammel P, Wiedenmann B, Van Cutsem E, Patyna S, Lu DR, Blanckmeister C, Chao R, Ruszniewski P. Sunitinib malate for the treatment of pancreatic neuroendocrine tumors. $N$ Engl J Med 2011:364:501-13.

8. Kulke MH, Lenz HJ, Meropol NJ, Posey J, Ryan DP, Picus J, Bergsland E, Stuart K, Tye L, Huang X, Li JZ, Baum CM, Fuchs CS. Activity of sunitinib in patients with advanced neuroendocrine tumors. J Clin Oncol 2008;26:3403-10.

9. Bajetta E, Catena L, Valente M, Bianco N, Bellomo F, Bombardieri E. New perspectives in the treatment of neuroendocrine tumours. Anticancer Res 2012;32:4193-200.

10. Sowa-Staszczak A, Pach D, Chrzan R, Trofimiuk M, Stefańska A, Tomaszuk M, Kołodziej M, Mikołajczak R, Pawlak D, Hubalewska-Dydejczyk A. Peptide receptor radionuclide therapy as a potential tool for neoadjuvant therapy in patients with inoperable neuroendocrine tumours (NETs). Eir J Nucl Med Mol Imaging 2011;38:1669-74

11. Strosberg J, Kvols L. Antiproliferative effect of somatostatin analogs in gastroenteropancreatic neuroendocrine tumors. World $J$ Gastroenterol 2010;16:2963-70.

12. Florio T. Somatostatin/somatostatin receptor signalling: phosphotyrosine phosphatase. Mol Cell Endocrinol 2008;286:40-8.

13. Florio T, Yao H, carey KD, Dillon TJ, Stork PJ. Somatostatin activation of mitogen-activated protein kinase via somatostatin receptor 1 (SSTR1). Mol Endocrinol 1999;13:24-37.

14. Serri O, Brazeau P, Kachra Z, Posner B. Octreotide inhibits insulin-like growth factor-1 hepatic gene expression in the hypophysectomized rat: evidence for a direct and indirect 
mechanism of action. Endocrinology 1992;130:1816-21.

15. Hoyer D, Bell GI, Berelowitz M, Epelbuam J, Feniuk W, Humphrey PP, O’Carroll AM, Patel YC, Schnbrunn A, Taylor JE. Classification and nomenclature of somatostatin receptor. Trends Pharmacol Sci 1995; 16:86-8.

16. Bauer W, Briner U, Doepfner W, Haller R, Huguenin R, Marbach P, Petcher TJ, Pless. SMS 201-995: a very potent and selective octapeptide analogue of somatostatin with prolonged action. Life Sci 1982;31:1133-40.

17. Bruns C, Weckbecker G, Raulf F, Kaupmann K, Schoeffter P, Hoyer D, Lübbert H. Molecular pharmacology of somatostatin-receptor subtyes. Ann N Y Acad Sci 1994;733:138-46.

18. Strosberg JR, Coppola D, Klimstra DS, Phan AT, Kulke MH, Wiseman GA, Kvols LK; North American Neuroendocrine Tumor Society (NANETS). The NANETS consensus guidelines for the diagnosis and management of poorly differentiated (highgrade) extrapulmonary neuroendocrine carcinomas. Pancreas 2010;39:799-800.

19. Sorbye H, Welin S, Langer SW, Vestermark LW, Holt N, Osterlund P, Dueland S, Hofsli E, Guren MG, Ohrling K, Birkemeyer E, Thiis-Evensen E, Biagini M, Gronbaek H, Soveri LM, Olsen IH, Federspiel B, Assmus J, Janson ET, Knigge U. Predictive and prognostic factors for treatment and survival in 305 patients with advanced gastrointestinal poorly differentiated neuroendocrine carcinoma (WHO G3): the NORDIC NEC study. Ann Oncol 2013;24:152-60.

20. Walter T, Bruneton D, Cassier PA, Hervieu V, Pilleul F, Scoazec JY, Chayvialle JA, Lombard-Bohas C. Evaluation of the combination 5-fluorouracil, dacarbazine, and epirubicin in patients with advanced well-differentiated neuroendocrine tumors. Clin Colorectal Cancer 2010;9:248-54.

21. Kulke MH, Hornick JL, Frauenhoffer C, Hooshmand S, Ryan DP, Enzinger PC, Meyerhardt JA, Clark JW, Stuart K, Fuchs CS, Redston MS. O6-methylguanine DNA methyltransferase deficiency and response to temozolomide-based therapy in patients with neuroendocrine tumors. Clin Cancer Res 2009; 15:338-45.

22. Bajetta E, Catena L, Procopio G, De Dosso S, Bichisao E, Ferrari L, Martinetti A, Platania M, Verzoni E, Formisano B, Bajetta R. Are capecitabine and oxaliplatin (XELOX) suitable treatments for progressing low-grade and high-grade neuroendocrine tumours? Cancer Chemother Pharmacol 2007;59:637-42.

23. Berruti A, Fazio N, Ferrero A, Brizzi MP, Volante M, Nobili E, Tozzi L, Bodei L, Torta M, D’Avolio A, Priola AM, Birocco N, Amoroso V, Biasco G, Papotti M, Dogliotti L. Bevacizumab plus octreotide and metronomic capecitabine in patients with metastatic well-to-moderately differentiated neuroendocrine tumors: the XELBEVOCT study. BMC Cancer 2014;14:184.

24. Koumarianou A, Antoniou S, Kanakis G, Economopoulos N, Rontogianni D, Ntavatzikos A, Tsavaris N, Pectasides D, Dimitriadis G, Kaltsas G. Combination treatment with metronomic temozolomide, bevacizumab and long-acting octreotide for malignant neuroendocrine tumours. Endocr Relat Cancer 2012;19:L1-4.

25. Brazeau P, Vale W, Burgus E, Ling N, Butcher M, Rivier J, Guillemin R. Hypothalamic polypeptide that inhibits the secretion of immunoreactive pituitary growth hormone. Science 1973;179:77-9.

26. Burgus R, Ling N, Butcher M, Guillemin R. Primary structure of somatostatin, a hypotalamic peptide that inhibits the secretion of pituitary growth hormone. Proc Natl Acad Sci U S A 1973;70:684-8.

27. Reisine T, Bell GI. Molecular biology of somatostatin receptors. Endocr Rev 1995; 16: 427-42.

28. Yamada Y, Post SR, Wang K, Tager HS, Bell GI, Seino S. Cloning and functional characterization of a family of human and mouse somatostatin receptors expressed in brain, gastrointestinal tract, and kidney. Proc Natl Acad Sci US A 1992;89:251-5.

29. Nilsson O, Kölby L, Wängberg B, Wigander A, Billig H, William-
Olsson L, Fjälling M, Forssell-Aronsson E, Ahlman H. Comparative studies on the expression of somatostatin receptor subtypes, outcome of octreotide scintigraphy and response to octreotide treatment in patients with carcinoid tumours. Br J Cancer 1998;77:632-7.

30. Reubi JC, Kvols LK, Waser B, Nagorney DM, Heitz PU, Charboneau JW, Reading CC, Moertel C. Detection of somatostatin receptors in surgical and percutaneous needle biopsy samples of carcinoids and islet cell carcinomas. Cancer Res 1990;50:5969-77.

31. Krenning EP, Kwekkeboom DJ, Bakker WH, Breeman WA, Kooij PP, Oei Hy, van Hagen M, Postema PT, de Jong M, Reubi JC. Somatostatin receptor scintigraphy with 111 In-STPA-D-Phe1 and 123-Tyr3-octreotide the Rotterdam experience with more than 1000 patients. Eur J Nucl Med 1993;20:716-31.

32. Panzuto F, Capurso G, Delle Fave G. Medical treatment of gastroentero-pancreatic endocrine tumours. In: Modlin IM, Oberg K. A century of advences in neuroendocrine tumor biology and treatment. Published by Felsenstein CCC; 2007. p. 364-9.

33. Strosberg JR, Fisher GA, Benson AB, Malin JL, GEPNET Treatment Consensus Panel, Cherepanov D, Broder MS, Anthony LB, Arslan B, Fisher GA, Gibbs JF, Greeno E, Iyer RV, Kim MK, Maples W, Philip PA, Strosberg J, Wolin EM. Systemic treatment in unresectable metastatic well-differentiated carcinoid tumors: consensus results from a modified delphi process. Pancreas 2013;42:397-404.

34. Rinke A, Müller HH, Schade-Brittinger C, Klose KJ, Barth P, Wied M, Mayer C, Aminossadati B, Pape UF, Bläker M, Harder J, Arnold C, Gress T, Arnold R; PROMID Study Group. Placebocontrolled, double-blind, prospective, randomized study on the effect of octreotide LAR in the control of tumor growth in patients with metastatic neuroendocrine midgut tumours: a report from the PROMID study Group. J Clin Oncol 2009;27:4565-63.

35. Janson ET, Oberg K. Long-term management of the carcinoid syndrome. Treatment with octreotide alone and in combination with alpha-interferon. Acta Oncol 1993;32:225-9.

36. Kvols LK, Moertel CG, O’Connell MJ, Schutt AJ, Rubin J, Hahn RG. Treatment of the malignant carcinoid syndrome. Evaluation of a long-acting somatostatin analogue. N Engl J Med 1986;315:663-6.

37. Rubin J, Ajani J, Schirmer W, Venook AP, Bukowski R, Pommier R, Saltz L, Dandona P, Anthony L. Octreotide acetate long-acting formulation versus open-label subcutaneous octreotide acetate in malignant carcinoid syndrome. J Clin Oncol 1999:17:600-6.

38. Rinke A, Wittenberg M, Schade-Brittinger C, Aminossadati B, Ronicke E, Gress TM, Müller HH, Arnold R; PROMID Study Group. Placebo controlled, double blind, prospective, randomized study on the effect of octreotide LAR in the control of tumor growth in patients with metastatic neuroendocrine midgut tumors (PROMID): Results on long-term survival (abstract). ASCO meeting Abstracts 2013;31:4030.

39. Sandostatin LAR Depot [prescribing information]. East Hanover, New Jersey: Novartis Pharmaceuticals Corporation; 2011. [cited 2014 Jul 30] Available from: http://www.accessdata.fda.gov/ scripts/cder/drugsatfda/.

40. Khan MS, El-Khouly F, Davies P, Toumpanakis C, Caplin ME. Long-term results of treatment of malignant carcinoid syndrome with prolonged release Lanreotide (Somatuline Autogel). Aliment Pharmacol Ther 2011;34:235-42.

41. O'Toole D, Ducreux M, Bommelaer G, Wemeau JL, Bouché O, Catus F, Blumberg J, Ruszniewski P. Treatment of carcinoid syndrome: a prospective crossover evaluation of lanreotide versus octreotide in terms of efficacy, patient acceptability, and tolerance. Cancer 2000;88:770-6.

42. Wymenga AN, Eriksson B, Salmela PI, Jacobsen MB, Van Cutsem EJ, Fiasse RH, Välimäki MJ, Renstrup J, de Vries EG, Oberg KE. Efficacy and safety of prolonged-release lanreotide in patients with gastrointestinal neuroendocrine tumors and hrmone-related symptoms. J Clin Oncol 1999;17:1111. 
43. Vinik A, Wolin EM, Audry H, Gomez-Panzani EL; ELECT Study Group. ELECT: A phase 3 study of efficacy and safety of lanreotide aurogel/depot (LAN) treatment for carcinoid syndrome in patients with neuroendocrine tumors (NETs) (abstract). ASCO Meeting Abstracts 2014;32:268.

44. Caplin ME, Pavel M, Cwikla JB, Phan AT, Sedlackova E, Cadio G, Wolin EM, Capdevilla J, Wall L, Rindi G, Langley A, Martinez S, Blumberg J, Ruszniewski P; CLARINET Investigators. Lanreotide in metastatic enteropancreatic neuroendocrine tumors. $N$ Engl $J$ Med 2014;371:224-33.

45. Bruns C, Lewis I, Briner U, Briner U, Meno-Tetang G, Weckbecker G. SOM-230: a novel somatostatin peptidomimetic with broad somatotropin release inhibiting factor (SRIF) receptor binding and a unique antisecretory profile. Eur J Endocrinol 2002;146:707-16.

46. Schimd HA. Pasireotide (SOM230): development, mechanism of action and potential applications. Mol Cell Endocrinol 2008;286:69-74.

47. Ben-Shlomo A, Melmed S. Pasireotide -- a somatostatin analog for the potential treatment of acromegaly, neurendocrine tumors and Cushing's disease. IDrugs 2007;10:885-95.

48. Modlin IM, Kidd M, Latich I, Zikusoka MN, Shapiro MD. Current status of gastrointestinal carcinoids. Gastroenterology 2005;128:1717-51.

49. Yao JC, Hassan M, Phan A, Dagohoy C, Leary C, Mares JE, Abdalla EK, Fleming JB, Vauthey JN, Rashid A, Evans DB. One hundred years after 'carcinoid': epidemiology of and prognostic factors for neuroendocrine tumors in 35,825 cases in the United States. $J$ Clin Oncol 2008;26:3063-72.

50. Lepage C, Rachet B, Coleman MP. Survival from malignant digestive endocrine tumors in England and Wales: a populationbased study. Gastroenterology 2007;132:899-904.

51. Pape UF, Berndt U, Mueller-Nordhorn J, Müller-Nordhorn J, Böhmig M, Roll S, Koch M, Willich SN, Wiedenmann B. Prognostic factors of long-term outcome in gastroenteropancreatic neuroendocrine tumours. Endocr Relat Cancer 2008;15:1083-97.

52. Modlin IM, Oberg K, Chung DC, Jensen RT, de Herder WW, Thakker RV, Caplin M, Delle Fave G, Kaltsas GA, Krenning EP, Moss SF, Nilsson O, Rindi G, Salazar R, Ruszniewski P, Sundin A. Gastroenteropancreatic neuroendocrine tumours. Lancet Oncol 2008;9:61-72.

53. Bosman FT, Carneiro F, Hruban RH, Thiese N, editors. World Health Organization Classification of Tumours. Pathology and Genetics. Tumors of the Digestive System. Lyon: IARC Press, 2010.

54. Travis WD, Brambilla E, Muller-Hermelink HK, Harris CC. Pathology and genetics of tumors of the lung, pleura, thymus and heart. Geneva: IARC Press, 2004

55. Moertel CG, Kvols LK, O'Connell MJ, Rubin J. Treatment of neuroendocrine carcinomas with combined etoposide and cisplatin. Evidence of major therapeutic activity in the anaplastic variants of these neoplasms. Cancer 1991;68:227-32.

56. Mitry E, Baudin E, Ducreaux M, Sabourin JC, Rufié P, Aparicio T, Aparicio T, Lasser P, Elias D, Duvillard P, Schlumberger M, Rougier P. Treatment of poorly differentiated neuroendocrine tumours with etoposide and cisplatin. Br J Cancer 1999;81:1351-5.

57. Fjällskog ML, Granberg DP, Welin SL, Eriksson C, Oberg KE, Janson ET, Eriksson BK. Treatment with cisplatin and etoposide in patients with neuroendocrine tumors. Cancer 2001; 92:1101-7.

58. Iwasa S, Morizane C, Okusaka T, Ueno H, Ikeda M, Kondo S, Tanaka T, Nakachi K, Mitsunaga S, Kojima Y, Hagihara A, Hiraoka N. Cisplatin and etoposide as first-line chemotherapy for poorly differentiated neuroendocrine carcinoma of the hepatobiliary tract and pancreas. Jpn J Clin Oncol 2010;40:313-8.

59. Lu ZH, Li J, Lu N, Zhang XT, Li J, Zhou J, Wang XC, Gong JF, Gao
J, Li Y, Shen L. Feasibility and efficacy of combined cisplatin plus irinotecan chemotherapy for gastroenteropancreatic neuroendocrine carcinomas. Med Oncol 2013;30:664.

60. Vélayoudom-Céphise FL, Duvillard P, Foucan L, Hadoux J, Chougnet CN, Leboulleux S, Malka D, Guigay J, Goere D, Debaere T, Caramella C, Schlumberger M, Planchard D, Elias D, Ducreux M, Scoazec JY, Baudin E. Are G3 ENETS neuroendocrine neoplasms heterogeneous? Endocr Relat Cancer 2013;20:649-57.

61. Heetfeld M, Chougnet CN, Olsen IH, Rinke A, Borbath I, Crespo G, Barriuso J, Pavel M, O’Toole D, Walter T; other Knowledge Network members. Characteristics and treatment of patients with G3 gastroenteropancreatic neuroendocrine neoplasms. Endocr Relat Cancer 2015;22:657-64.

62. Hentic O, Hammel P, Couvelard A, Rebours V, Zappa M, Palazzo M, Maire F, Goujon G, Gillet A, Lévy P, Ruszniewski P. FOLFIRI regimen: an effective second-line chemotherapy after failure of etoposide-platinum combination in patients with neuroendocrine carcinomas grade 3. Endocr Relat Cancer 2012;19:751-7.

63. Welin S, Sorbye H, Sebjornsen S, Knappskog S, Busch C, Oberg $\mathrm{K}$. Clinical effect of temozolomide- based chemotherapy in poorly differentiated endocrine carcinoma after progression on first-line chemotherapy. Cancer 2011;117:4617-22.

64. Kouvaraki MA, Ajani JA, Hoff P, Wolff R, Evans DB, Lozano R, Yao JC. Fluorouracil, doxorubicin, and streptozotocin in the treatment of patients with locally advanced and metastatic pancreatic endocrine carcinomas. J Clin Oncol 2004;22:4762-71.

65. Bajetta E, Rimassa L, Carnaghi C, Seregni E, Ferrari L, Di Bartolomeo M, Regalia E, Cassata A, Procopio G, Mariani L. 5-Fluorouracil, dacarbazine, and epirubicin in the treatment of patients with neuroendocrine tumors. Cancer 1998;83:372-8.

66. Strosberg JR, Fine RL, Choi J, Nasir A, Coppola D, Chen DT, Helm J, Kvols L. First-line chemotherapy with capecitabine and temozolomide in patients with metastatic pancreatic endocrine carcinomas. Cancer 2011;117:268-75.

67. Cassier PA, Walter T, Bohas CL, Ardisson P, Perol M, Paillet C, Chayvialle JA, Scoazec JY, Hervieu V, Bohas CL. Gemcitabine and oxaliplatin combination chemotherapy for metastatic welldifferentiated neuroendocrine carcinomas. Cancer 2009;115: 3392-9.

68. Spada F, Antonuzzo L, Marconcini R, Radice D, Antonuzzo A, Ricci S, Di Costanzo F, Fontana A, Gelsomino F, Luppi G, Nobili E, Galdy S, Cella CA, Sonzogni A, Pisa E, Barberis M, Fazio N. Oxaliplatinbased chemotherapy in advanced neuroendocrine tumors: clinical outcomes and preliminary correlation with biological factors Neuroendocrinology 2016 Jan 21; doi:10.1159/000444087.

69. Brizzi MP, Berruti A, Ferrero A, Milanesi E, Volante M, Castiglione F, Birocco N, Bombaci S, Perroni D, Ferretti B, Alabiso O, Ciuffreda L, Bertetto O, Papotti M, Dogliotti L. Continuous 5-fluorouracil infusion plus long acting octreotide in advanced well-differentiated neuroendocrine carcinomas. A phase II trial of the Piemonte oncology network. BMC Cancer 2009;9:388.

70. Ceppi P, Volante M, Ferrero A, Righi L, Rapa I, Rosas R, Berruti A, Dogliotti L, Scagliotti GV, Papotti M. Thymidylate synthase expression in gastroenteropancreatic and pulmonary neuroendocrine tumors. Clin Cancer Res 2008;14:1059-64.

71. Lim E, Goldstraw P, Nicholson G, Travis WD, Jett JR, Ferolla P, Bomaji J, Rusch VW, Asamura H, Skogseid B, Baudin EE, Caplin M, Kwekkeboom D, Brambilla E, Crowley J. Proceedings of the IASLC International Workshop on Advances in Pulmonary Neuroendocrine Tumors 2007. J Thorac Oncol 2008;3:1194-201.

72. Crona J, Björklund P, Welin S, Kozlovacki G, Öberg K, Granberg D. Treatment, prognostic markers and survival in thymic neuroendocrine tumours. A study from a single tertiary referral centre. Lung Cancer 2013;79:289-93. 